\title{
Biliary Tubulovillous Adenoma
}

Saad Khan ${ }^{1,2}$, Peter Evans ${ }^{3}$ and Leon Fisher ${ }^{2}$

${ }^{1}$ Department of Gastroenterology and Liver Transplant Unit, Austin Health,

Melbourne, Victoria, Australia

2 Departinet

Department of Gastroenterology, Peninsula Health, Melbourne, Victoria, Australia

${ }^{3}$ D.nartment of Surgery, Peninsula Health, Melbourne, Victoria, Australia

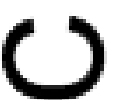

First/Cgrresponding Author: Dr Saad Khan

Departryent of Gastroenterology and Liver Transplant Unit

Level___Harold Stokes Building, Austin Health

145 Studley Road, Heidelberg, Victoria, Australia 3084

Email.aadkhan2304@gmail.com Ph: +61 403798622

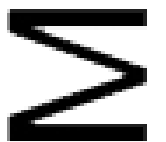

Second Author: Dr Peter Evans

De artment of Surgery, Peninsula Health

2 astings Rd, Frankston, VIC, Australia 3199

Thirarsenior Author: Dr Leon Fisher

Denartment of Gastroenterology, Peninsula Health

2 Hastings Rd, Frankston, VIC, Australia 3199

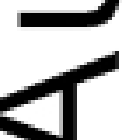

Disclosure Statement

This is the author manuscript accepted for publication and has undergone full peer review but has not been through the copyediting, typesetting, pagination and proofreading process, which may lead to differences between this version and the Version of Record. Please cite this article as doi: $10.1111 /$ jgh.13660

This article is protected by copyright. All rights reserved. 
None of the authors have any financial grants or other sources of funding to disclose

\section{Acknowledgements}

Nil

An 86-year-old man presented with nausea, lethargy and a mixed pattern derangement of his liver function tests with normal synthetic function. His liver biochemistry

shomedowing: total bilirubin $0.53 \mathrm{mg} / \mathrm{dL}$ (normal, $<1.2 \mathrm{mg} / \mathrm{dL}$ ), alkaline phđsphatase 200 IU/L (normal, 40-140 IU/L)), gamma-glutamyl transpeptidase 418 IU/C (ngrmal, 10-50 IU/L), aspartate aminotransferase $280 \mathrm{IU} / \mathrm{L}$ (normal, 15-50 IU/C) a anine aminotransferase $288 \mathrm{IU} / \mathrm{L}$ (normal, 7-40 IU/L). This was on a baolyond of previous cholecystectomy for cholelithiasis and a left hemicolectomy for colonic adenocarcinoma 10 years prior to this presentation. There was no history of artorol consumption, smoking, weight loss or bowel symptoms. Abdominal ultis graphy demonstrated a dilated $14 \mathrm{~mm}$ common bile duct (CBD) and features suggactive of a common hepatic duct mass (Fig. 1). The patient's lipase, serum immunoglobulin-G4 levels, anti-mitochondrial antibody, carcinoembryonic antigen andcancer antigen19-9 were all normal. Magnetic resonance cho ang ppancreatography could not be performed as the patient had a cardiac pacemoler. Endoscopic retrograde cholangiopancreatography (ERCP) revealed dilated intrahepatic bile ducts with an irregular filling defect in the common hepatic ducrjug distal to the porta hepatis. Balloon trawls retrieved three soft tissue fragmens each $7 \mathrm{~mm}$ in diameter and a plastic biliary stent was successfully placed. Histopathology showed closely packed tubular structures and slender villi formed by 
uniform columnar cells, confirming a diagnosis of tubulovillous adenoma (TVA) with moderate grade dysplasia (Fig. 2).

After discussion at a hepatopancreatobiliary multidisciplinary meeting, the patient underwent resection of the porta hepatis with Roux-en-Y hepaticojejunostomy. Intraoperative findings included a polypoid lesion $(18 \times 12 \times 7 \mathrm{~mm})$ in the proximal CBD (Fi nothattached to the duct wall. Histopathology confirmed the lesions to be polypoid TVAs. The excised common hepatic duct contained a small amount of residual ade 10 mg tous tissue consistent with incomplete retrieval at ERCP. While TVAs commonly arise from colonic and rectal mucosa, those originating from the biliary system are exceedingly rare. Due to their rarity, biliary TV ris are often overlooked as a cause of biliary obstruction, and often confused for oth natignant lesions including cholangiocarcinoma, lymphoma and carcinoid tumos Although the adenoma to carcinoma transformation risk is undetermined, the risk or malignancy is generally considered to be similar to adenomas arising from other regions of the gastrointestinal tract. While endoscopic resection by ERCP has bee proposed, due to the high risk of incomplete resection and adenoma recurrence, compargical excision of the adenoma-containing bile duct appears to be the treatment of choice.

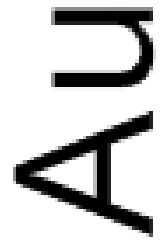




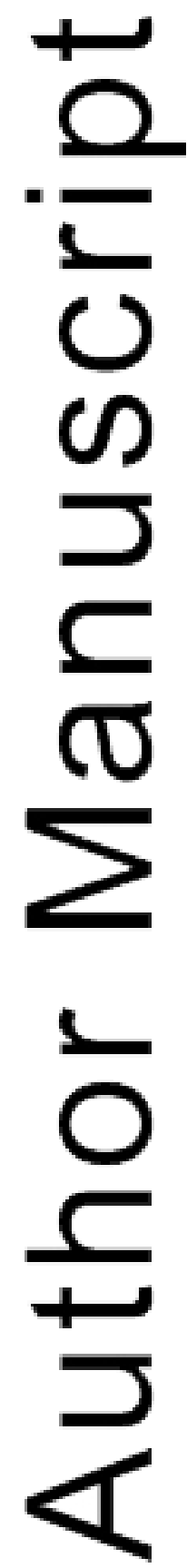

This article is protected by copyright. All rights reserved. 


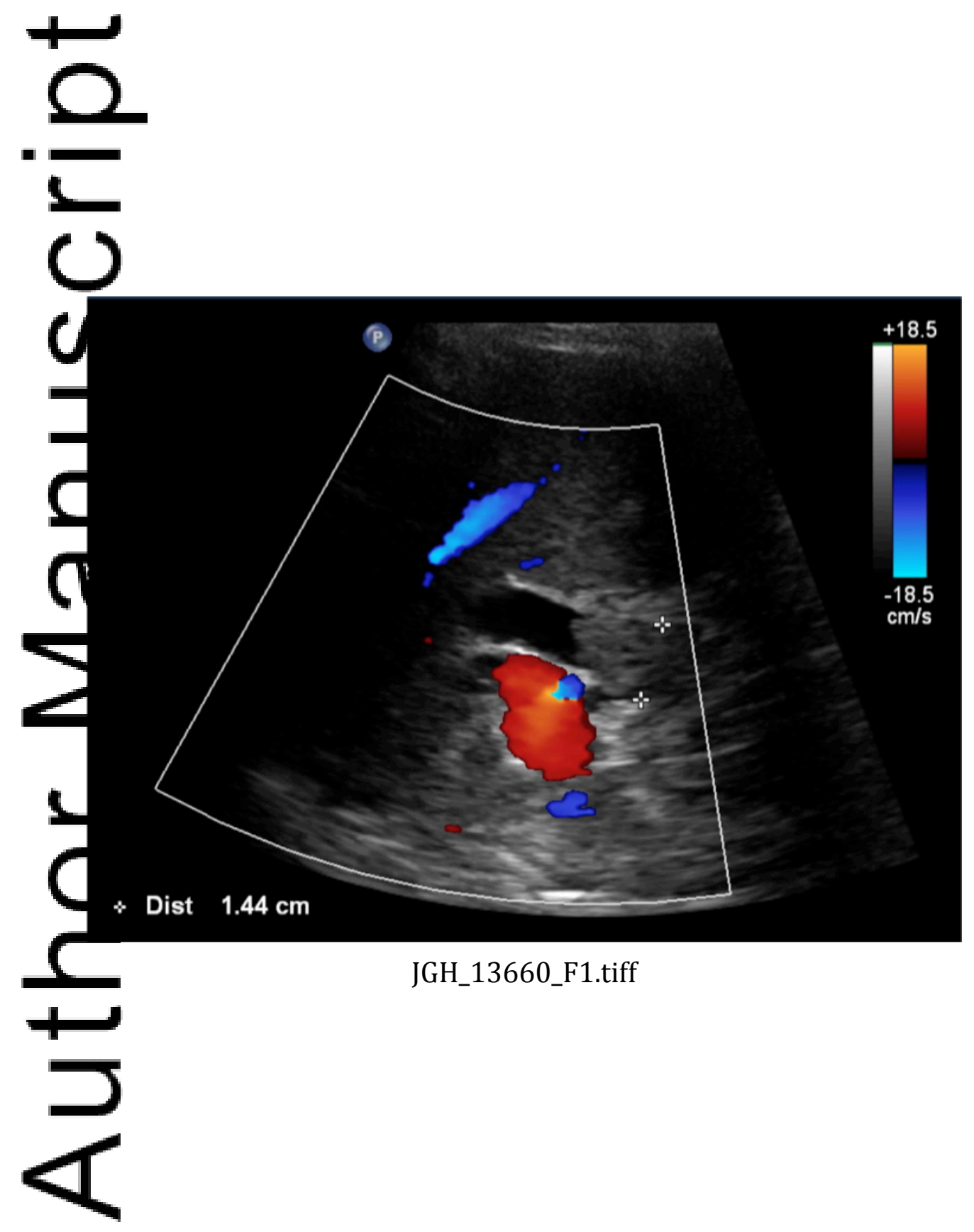

This article is protected by copyright. All rights reserved. 


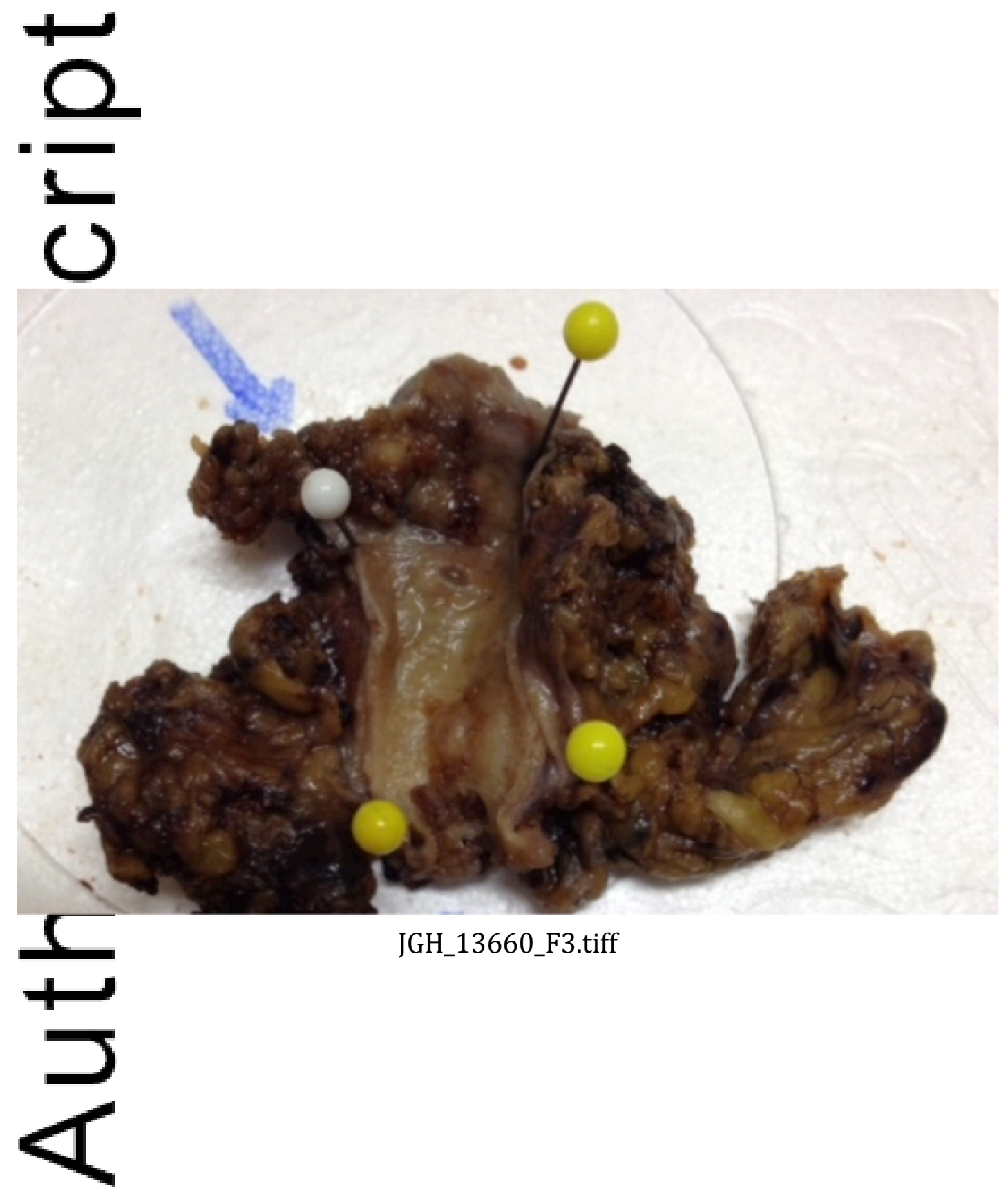

This article is protected by copyright. All rights reserved. 


\section{University Library}

\section{- M M I E R R A A gateway to Melbourne's research publications}

Minerva Access is the Institutional Repository of The University of Melbourne

Author/s:

Khan, S;Evans, P;Fisher, L

Title:

Gastrointestinal: Biliary tubulovillous adenoma

Date:

2017-08-01

Citation:

Khan, S., Evans, P. \& Fisher, L. (2017). Gastrointestinal: Biliary tubulovillous adenoma. JOURNAL OF GASTROENTEROLOGY AND HEPATOLOGY, 32 (8), pp.1423-1423. https:// doi.org/10.1111/jgh.13660.

Persistent Link:

http://hdl.handle.net/11343/293233 